\title{
Does interpersonal sensitivity and paranoid ideation predict nomophobia: an analysis with a young adult sample
}

\author{
Tuğba Yılmaz ${ }^{1}$ (D) Ece Bekaroğlu² (D) \\ Accepted: 11 February 2021 / Published online: 24 February 2021 \\ (C) The Author(s), under exclusive licence to Springer Science+Business Media, LLC part of Springer Nature 2021
}

\begin{abstract}
Nomophobia has been studied extensively due to its negative effects on human health and psychology. In terms of clinical psychology, nomophobia has been linked consistently to depression and anxiety. Studies also investigated whether it is a dependency, an impulse control problem, an obsession or a phobia; however, no clear clinical representation was confirmed. Although it was proposed to be added as an official diagnosis to DSM-5, these attempts were inconclusive. In this study, nomophobia was examined clinically by SCL-90 factors. A hierarchical regression analysis was performed by controlling anxiety, depression, phobia and obsessions by putting them in the first step. At the next step, paranoid ideation was entered while interpersonal sensitivity was introduced at the last step. The variables were assigned according to the steps according to their connections confirmed by the literature, the correlation coefficients and $\beta$ weights obtained in the current study. The hierarchical regression analysis confirmed that after controlling anxiety, depression, phobia and obsessions, nomophobia is explained by interpersonal sensitivity. Paranoid ideation is also an important variable in step 2, but it lost its significance in the last step. Nevertheless, it was thought that what makes people sensitive to interpersonal issues is a kind of fear of missing out others' experiences (FoMO) which is related to nomophobia. This fear of missing out might prepare people to constantly check on mobile phones thinking paranoid about what they might have been missing or deprived of. Clinical implications and limitations were discussed.
\end{abstract}

Keywords Nomophobia - Interpersonal sensitivity · Paranoia · Fear of missing out (FoMO) - Clinical psychology · Psychopathology

Nowadays, the internet and mobile phone usage have become an important part of life (Adnan \& Gezgin, 2016). The use of mobile phones has increased considerably due to the development of the devices' capacities and the ease of internet access (Bian \& Leung, 2014). Mobile phone subscriptions were found to be 103.5 per 100 inhabitants' worldwide (International Telecommunication Union, 2017).

The advantages of mobile phones can be listed as providing access to large data for a small cost, facilitating communication with social networks (Boonstra, Larsen, \& Christensen, 2015), contributing access to information that promotes academic and business life (Apuke \& Iyendo, 2018). Especially, during the coronavirus pandemic, the use of mobile phones

Tuğba Yilmaz

tugba.yilmaz.psy@gmail.com

1 İzmir Bakırçay University, İzmir, Turkey

2 Ankara Hacı Bayram Veli University, Ankara, Turkey has increased, and in many countries, mobile phones have become an important means of communication due to physical distance.

Although the use of mobile phones has some advantages, it has been stated that excessive use of mobile phones may cause several psychological disorders (Bragazzi \& Del Puente, 2014). For instance, nomophobia, a new phobia of the modern era, is the fear when the individual cannot access his/her mobile phone and cannot communicate over (King, Valença, \& Nardi, 2010). Later, King et al. (2014) updated this definition and stated that nomophobia is the fear or phobia of being away from a mobile phone and it includes a group of symptoms and behaviors related to the usage of mobile phones. According to Packham (2015), individuals with nomophobia passes four stages, namely, fear of not able to communicate, fear of losing connection, fear of not able to access information, and fear of being unable to access mobile phone. People with nomophobia has fear of missing out events and messages posted on social media applications (FOMO; Yıldırım \& Correra, 2015). When their mobile phone is out of charge or 
they forget their mobile phones, they feel anxiety and stress. These people try to switch on their mobile phones during the day and most probably take their mobile to the bed. According to the American Psychiatric Association (2013), nomophobia can be considered as a specific phobia since people terrify no mobile phone condition. However, nomophobia has not been in DSM-5 with its diagnostic criteria. Therefore, this condition is compared with other psychopathologies (Bekaroğlu \& Y1lmaz, 2020) such as separation anxiety (Han, Kim, \& Kim, 2017), obsessive compulsive disorder (Șar \& Ișıklar, 2012), panic disorder (King et al., 2014), impulsive behavior (Siddiqui \& Ali 2015, Y1ldız Durak 2019) and internet addiction (King, Valença, Silva, Sancassioni, \& Nardi, 2012).

Social anxiety, fear of relating, panic disorder, impulsiveness, low self-esteem and low self-efficacy may be related with nomophobia (Bhattacharya, Bashar, Srivastava, \& Singh, 2019; Sales, Silva, \& Lima, 2018). Moreover, nomophobia is correlated with psychological symptoms such as depression and anxiety (Yen et al., 2009; Thomée, Härenstam, \& Hagberg, 2011; Harwood, Dooley, Scott, \& Joiner, 2014; Lemola, Perkinson-Gloor, Brand, DewaldKaufmann, \& Grob, 2015; Elhai, Levine, Dvorak, \& Hall, 2016; Elhai, Dvorak, Levine, \& Hall, 2017; Wolniewicz, Tiamiyu, Weeks, \& Elhai, 2018), insomnia (Yogesh, Abha, \& Priyanka, 2014); feelings of rejection, loneliness, insecurity; addiction of mobile phone (Bhattacharya, Bashar, Srivastava, \& Singh, 2019), interpersonal sensitivity, paranoia (Babadi-Akashe, Zamani, Abedini, Akbari, \& Hedayati, 2014) and low self-esteem (King et al., 2014).

In the literature, young age or the ages between 18 and 25 is found to be a risk factor for nomophobia than older ages (Bianchi \& Phillips 2005, Bragazzi \& Del Puente 2014, Ylldiz Durak 2019) since they are the biggest consumer party worldwide (Head \& Ziolkowski, 2012). As this age group is attending university, nomophobia has been an important subject that has been studied with university students in the literature. For instance, Southern Europe university students display lower levels of self-perception of the mobile phone use than Northern Europe Students (López-Fernández et al., 2017). In Leonardi and colleagues study (2006), university students from United States are more likely to use mobile phones to avoid loneliness and connect other people than Latin American and European university students. In this age group, separation anxiety, social phobia and total anxiety scores are positively correlated with nomophobia total score (Kuscu, Gumustas, Rodopman Arman, \& Goksu, 2020). In other words, in the young adult age group, anxious personality traits, sensitivity and anxiety in human relationships may be associated with nomophobia. In terms of gender differences, several studies found that females are found to be more prone to nomophobia than males (Arpaci, 2019; Elhai, Levine, O'Brien, \& Armour, 2018). However, other studies indicated that males are more inclined to have nomophobia (Aljomaa,
Qudah, Albursan, Bakhiet, \& Abduljabbar, 2016; Jilisha, Venkatachalam, Menon, \& Olickal, 2019).

The objectives of the current study were to find out the relationship (if any) between the psychopathological symptoms and nomophobia in the university students who are a young adult group. The hypothesis was to find the psychopathological symptoms that have predictive ability of nomophobia when controlling for anxiety, phobia, depression and obsessive compulsive.

\section{Method}

\section{Participants}

This study consisted of 331 participants from İzmir Bakırçay University and Ankara Hacı Bayram Veli University. Participants were recruited by convenience sampling method since the authors conducted this study from their workplaces. They completed the survey via an online survey system called "Qualtrics: Online Survey Software \& Insight Platform". Sixty participants who did not complete the entire questionnaire were excluded from the study; therefore, the data analysis was conducted with 271 participants. This number of participants were enough to conduct an $80 \%$ powered hierarchical multiple regression including two predictors (Brysbaert, 2019). Although the ages of the participants in the study varied between 18 and 44, they were all university students which was the inclusion criteria. $95.5 \%$ of the participants were between the ages of 18 and $25(N=259)$, in other words in early adulthood period. $87.1 \%$ of the participants are female $(N=$ $236)$ while $12.9 \%(N=35)$ of the participants are male. When asked about their socioeconomic status, $9.2 \%$ of the participants $(N=25)$ stated that they were low, $89.7 \%$ were middle $(N=243)$ and $1.1 \%$ were high status $(N=3)$. While all of the participants stated that they have mobile phones, $93 \%(N=$ 252) stated that their mobile phones are smartphones.

\section{Instruments}

\section{Demographic Information Form}

This form includes questions about the age, gender, socioeconomic status and mobile phone use of the participants.

\section{SCL-90-R}

The SCL-90-R was developed by Deragotis $(1977,1994)$ and adapted to Turkish by Dağ (1991) with high reliability and validity values. It is a 90 item self-report to screen for a broad range of psychopathological symptoms. Items are rated on a 
5-point Likert type scale ( $0=$ none, $4=$ extremely) and has 9 subscales namely, somatization, obsessive compulsive, interpersonal sensitivity, anger-hostility, depression, anxiety, paranoid ideation, phobic anxiety and psychoticism. It is not only a well-researched inventory but also used in clinical psychology and psychiatry frequently. Cronbach's alpha internal consistency reliability of the scale was found as .97 in this study.

\section{The Nomophobia Questionnaire}

The Nomophobia Questionnaire was developed by Yildirim and Correia (2015) and adapted to Turkish by Yıldırım, Sumuer, Adnan and Y1ldırım (2016). It is a 20 item selfreport in order to address four dimensions of nomophobia: not being able to communicate, losing connectedness, not being able to access information, giving up convenience. Items of the questionnaire are rated using a 7-point Likert type scale ranging from 1 to 7 ( $1=$ strongly disagree, $7=$ strongly agree). In the original adaptation study, Cronbach's alpha value was indicating high reliability. In this study, Cronbach's alpha was found as .93 .

\section{Procedure}

After the approval of the ethics committee of Ankara Hac1 Bayram Veli University, instruments were transformed into the online survey system "Qualtrics". Therefore, the instruments were administered individually to undergraduate students of different departments of İzmir Bakırçay University and Ankara Hacı Bayram Veli University. Consent was received from participants of the study and they were informed about the purpose of the study and assured that they can be withdrawn from the study at any time. Applications of the questionnaires took $15 \mathrm{~min}$. After the administration of the questionnaires, all the participants were debriefed about the details of the study and the contact information of the researchers. The data gathering process was between October 2019 and January 2020. In order to test the hypotheses of the current study, IBM SPSS Statistics 25 was used.

\section{Results}

\section{Statistical Analyses}

After excluding participants who did not answered the questionnaire, normality of the SCL-90 factors and nomophobia subscales and total score was tested. Skewness and kurtosis values of each of the variables were in between -2 and +2 and they were accepted as normal (George \& Mallery, 2010). Then, SCL-90 factors were correlated with nomophobia to have an initial understanding of the relation between psychopathological symptoms and nomophobia. Interpersonal sensitivity and paranoid ideation were selected and further tested whether they were predicting nomophobia after controlling for anxiety, depression, phobia, and obsessive compulsive by hierarchical regression analysis.

\section{Correlations among Variables}

Zero order correlation coefficients among the measures were examined to investigate the relationships among SCL-90 and nomophobia questionnaires and their subscales included in the current study (see Table 1). SCL-90 had 10 subscales whereas the nomophobia questionnaire had 4 subscales.

These result suggested that nomophobia total scores were correlated highest with interpersonal sensitivity $(r=.31$, $p<.001)$ whereas the second highest correlation was with paranoid ideation $(r=.29, p<.001)$. Phobic anxiety, obsessive compulsive and depression were also correlated highly with nomophobia total scores.

When subscales of nomophobia were evaluated, it was obvious that interpersonal sensitivity achieved the highest significant correlations with all subscales of nomophobia; namely, not being able to access information, losing connectedness, not being able to communicate, and giving up convenience. Paranoid ideation had high correlations with most of the nomophobia subscale except losing connectedness subscale of nomophobia. Other SCL-90 subscales such as obsessive compulsive and depression were also correlated with all nomophobia subscales but not with the losing connectedness subscale of nomophobia.

\section{Regressions}

To further see the predictive power of SCl-90 subscales with nomophobia, first a multiple linear regression was performed to predict total nomophobia from 10 subscales of SCl-90. The model was significant. SCL-90 subscales explained a significant amount of the variance in total nomophobia, $F(10$, $260)=3.845, p<.001, R^{2}=.13, R^{2}$ adjusted $=.10$. The highest regression coefficient was for paranoid ideation $(\beta=1.003)$ and the second highest was for interpersonal sensitivity ( $\beta=.66$ ); however, all regression coefficients were insignificant. This result must be due to the fact that SCL-90 subscales were not independent of each other which was understandable clinically; as a result of this, only theoretically related subscales of SCL-90 should be employed to see a clear picture of nomophobia from a clinical viewpoint.

To understand which SCL-90 subscale accounted for most variance in total nomophobia, a hierarchical regression analysis was employed (See Table 2). First, theoretically related variables were entered and these were obsessive compulsive, phobia, depression and anxiety. Next, paranoid ideation was added to the model due to its string correlations with the 
Table 1 Correlation among measures

\begin{tabular}{|c|c|c|c|c|c|c|c|c|c|c|c|c|c|c|c|}
\hline & Subscales & 1 & 2 & 3 & 4 & 5 & 6 & 7 & 8 & 9 & 10 & 11 & 12 & 13 & 14 \\
\hline \multirow[t]{10}{*}{ SCL-90 } & 1.Somatization & - & & & & & & & & & & & & & \\
\hline & 2. Obsessive compulsive & $.59^{* * *}$ & - & & & & & & & & & & & & \\
\hline & 3.Interpersonal sensitivity & $.50^{* * *}$ & $.71^{* * *}$ & - & & & & & & & & & & & \\
\hline & 4. Depression & $.61^{* *}$ & $.74^{* *}$ & $.80^{* *}$ & - & & & & & & & & & & \\
\hline & 5. Anxiety & $.73^{* *}$ & $.69^{* *}$ & $.67^{* *}$ & $.77^{* *}$ & - & & & & & & & & & \\
\hline & 6. Hostility & $.52^{* *}$ & $.49^{* *}$ & $.54^{* *}$ & $.61^{* *}$ & $.59^{* *}$ & - & & & & & & & & \\
\hline & 7. Phobic anxiety & $.61^{* *}$ & $.57^{* *}$ & $.62^{* *}$ & $.64^{* *}$ & $.74^{* *}$ & $.56^{* *}$ & - & & & & & & & \\
\hline & 8. Paranoid ideation & $.50^{* *}$ & $.62^{* *}$ & $.76^{* *}$ & $.72^{* *}$ & $.61^{* *}$ & $.61^{* *}$ & $.53^{* *}$ & - & & & & & & \\
\hline & 9.Psychoticism & $.61^{* * *}$ & $.67^{* *}$ & $.71^{* *}$ & $.78^{* *}$ & $.76^{* *}$ & $.59^{* *}$ & $.66^{* *}$ & $.68^{* *}$ & - & & & & & \\
\hline & 10.Additional items & $.64^{* *}$ & $.62^{* *}$ & $.58^{* *}$ & $.69^{* *}$ & $.66^{* *}$ & $.52^{* *}$ & $.56^{* *}$ & $.56^{* *}$ & $.65^{* *}$ & - & & & & \\
\hline \multirow[t]{5}{*}{ Nomophobia } & $\begin{array}{l}\text { 11. Not being able to access } \\
\text { information }\end{array}$ & .11 & $.15^{*}$ & $.27^{* *}$ & $.21^{* *}$ & $.21^{* *}$ & $.17^{* *}$ & $.26^{* *}$ & $.25^{* *}$ & $.24^{* *}$ & $.12^{*}$ & - & & & \\
\hline & 12. Losing connectedness & .04 & .11 & $.16^{*}$ & .10 & .10 & -.00 & .10 & .10 & .09 & .04 & $.42^{* *}$ & - & & \\
\hline & 13. Not being able to communicate & .11 & $.25^{* *}$ & $.28^{* *}$ & $.22^{* *}$ & $.23^{* *}$ & $.17^{* * *}$ & $.24^{* *}$ & $.27^{* *}$ & $.22^{* *}$ & .12 & $.60^{* *}$ & $.60^{* *}$ & - & \\
\hline & 14. Giving up convenience & .06 & $.22^{* *}$ & $.30^{* *}$ & $.22^{* *}$ & $.12^{*}$ & $.13^{*}$ & $.15^{*}$ & $.31^{* *}$ & $.19^{* *}$ & .07 & $.44^{* *}$ & $.33^{* *}$ & $.60^{* *}$ & - \\
\hline & 15. Total & .10 & $.23^{* *}$ & $.31^{* *}$ & $.23^{* *}$ & $.21^{* *}$ & $.15^{*}$ & $.24^{* *}$ & $.29^{* *}$ & $.23^{* *}$ & .11 & $.76^{* *}$ & $.77^{* *}$ & $91^{* * *}$ & $.72^{* *}$ \\
\hline
\end{tabular}

outcome variable. In the third step, interpersonal sensitivity was entered into the equation.

ANOVA results showed that all three models were significant, suggesting that the final model significantly improved the ability to predict total nomophobia. At step I, obsessive compulsive, depression, anxiety, and phobia subscales of

Table 2 Summary of hierarchical regression analysis for SCL-90 subscales predicting total nomophobia

\begin{tabular}{lrrrrr}
\hline Variable & \multicolumn{1}{l}{$\beta$} & \multicolumn{1}{l}{$t$} & $R$ & $R^{2}$ & $\Delta R 2$ \\
\hline Step 1 & & & .27 & .073 & .073 \\
Anxiety & -.16 & -.42 & & & \\
Phobia & .84 & 1.73 & & & \\
Depression & .21 & .88 & & & \\
Obsessive compulsive & .38 & 1.15 & & & \\
Step 2 & & & .31 & .095 & .023 \\
Anxiety & -.21 & -.55 & & & \\
Phobia & .77 & 1.60 & & & \\
Depression & -.05 & -.21 & & & \\
Obsessive compulsive & .25 & .75 & & & \\
Paranoid ideation & 1.24 & $2.57^{*}$ & & & \\
Step 3 & & & .33 & .11 & .015 \\
Anxiety & -.17 & -.49 & & & \\
Phobia & .60 & 1.23 & & & \\
Depression & -.24 & -.88 & & & \\
Obsessive compulsive & .09 & .25 & & & \\
Paranoid ideation & .78 & 1.48 & & & \\
Interpersonal sensitivity & .78 & $2.08^{*}$ & & & \\
\hline
\end{tabular}

*Note. $p<.05$
SCL-90 contributed significantly to the regression model $F(4,266)=5.23, p<.001$ and accounted for $7.3 \%$ of the variation in total nomophobia. Adding paranoid ideation to the regression model explained an additional $9.5 \%$ of the variation in nomophobia and this change in $R^{2}$ was significant, $F(5$, $265)=5.59, p<.001$. Finally, the addition of interpersonal sensitivity to the regression model explained an additional $1.5 \%$ of the variation in nomophobia and this change in $R^{2}$ was significant, $F(6,264)=5.44, p<.001$. At step 2, paranoid ideation was a significant predictor of the outcome variable. Moreover, interpersonal sensitivity forced to the step 3 was also an important predictor of total nomophobia.

\section{Discussion}

Due to its novelty and popularity, nomophobia is a topic that has been extensively studied by many areas such as education, psychology, medicine, and community health. Revision of the literature suggests that the relation between nomophobia and demographic variables such as gender, age, the occupation has been studied lately (Rodriguez-Garcia, Monero-Guerrero, \& Belmonte, 2020). In addition to this, the link between nomophobia and psychological variables has been studied. The psychological variables were anxiety, panic disorder, stress, depression, avoidance, hostility, obsessiveness, fear of missing out (FOMO), five-factor personality, mindfulness, loneliness and self-happiness (Rodriguez-Garcia et al., 2020). Moreover, social anxiety, fear of relating, impulsiveness, low self-esteem and low self-efficacy were also investigated in the development of nomophobia (Bekaroğlu \& 
Y1lmaz, 2020; Bhattacharya, et al., 2019; Sales, et al., 2018). The psychological variables in these researchers demonstrate that nomophobia worth evaluating reliable in terms of clinical psychology. Rather than using different psychological measurement tools and explaining their relation with nomophobia, the role of a strong clinical construct should be investigated in nomophobia.

Fulfilling this objective, the current study aimed to understand nomophobia in terms of clinical constructs such as somatization, obsessive compulsive, interpersonal sensitivity, anger-hostility, depression, anxiety, paranoid ideation, phobic anxiety and psychoticism. Because nomophobia is not yet an official diagnosis (Bragazzi \& Del Puente, 2014) and young adults were under the risk of nomophobia (Bianchi \& Phillips 2005, Bragazzi \& Del Puente 2014, Yildız Durak 2019) a sample of young adults were recruited. Adawi et al. (2019) with Italian volunteers performed a similar study. The difference between Adawi et al. (2019) and this study is just the objective of the study. The objective of Adawi et al. (2019) was to study the psychometric properties of the Brief Symptom Inventory (aka. SCL-90) in nomophobic subjects. On the contrary, the one that pursued in this study was to understand clinical structure lying behind nomophobia by acknowledging that it is not yet an official diagnosis. Hence, rather than calculating the sum of the scores (GSI) in brief symptom inventory (SCl-90) the authors preferred to explore the role of factors of SCL-90 on nomophobia.

The results suggested important conclusions. Correlation results between SCL-90 factors and nomophobia factors were very similar to those in Adawi et al. (2019) study. Multiple regression results yielded that factors of SCL-90 were strong enough to explain the variance in nomophobia; however, none of the factors (SCL-90 subscales) were significant on their own. After realizing this, a hierarchical regression analysis was performed by entering anxiety, depression, obsessive compulsive and phobic anxiety in step 1, introducing paranoid ideation at step 2 and interpersonal sensitivity at the last step. The reason for choosing the first step factors was the strong connection of anxiety, depression, phobia and obsessions with nomophobia, stated by the current literature (Bekaroğlu \& Yılmaz, 2020; Rodriguez-Garcia et al., 2020) and confirmed by the correlation results of the current study. Step 2 and 3 factors were chosen by these factors' high correlation coefficients and $\beta$ weights in linear multiple regression results.

Hierarchical regression results yielded that nomophobia has some roots in depression, anxiety, obsessions, and phobia given the significance of the model at the first step. However, none of these variables was significant on their own. This result showed that nomophobia is related but not limited to depression, anxiety, obsessions, and phobia. To further the investigation, the authors wanted to control these larger constructs by introducing them into step 1 . Given the size of the significant and positive correlation coefficients and relatively high $\beta$ weights in linear multiple regression results; paranoid ideation was introduced to step 2 and interpersonal sensitivity to step 3 . The aim of assigning factors in step 2 and step 3 was also related to the current literature. Paranoid ideation, on the other hand, has not yet been indicated importance in nomophobia studies. The current study highlighted that FoMO or interpersonal sensitivity is very critical for nomophobia; in addition; FoMO might be due to a paranoid or a skeptical viewpoint. Individuals might have a kind of thinking that others have richer experiences than they might articulate; hence, they think they should be skeptical in following their representations in social media. This kind of paranoid thinking might be the motivating factor for people to become sensitive to other people and their lives; hence, they want to have constant access to smartphones and social media to check them. This result could be clinically important in the investigation of nomophobia.

It has been suggested that the clinical representation of nomophobia is similar to specific phobias (Bragazzi \& Del Puente, 2014); however, nomophobia is more related to larger anxiety symptomatology. Rather than fitting nomophobia into one existing diagnosis in DSM-5 (American Psychiatric Association, 2013), the clinical characteristics of nomophobia were explored. These results supported the notion that nomophobia is not limited to simple phobia. Hierarchical regression analysis showed that after controlling anxiety, paranoid thinking and interpersonal sensitiveness were significant predictors of total nomophobia. Therefore results illuminated that nomophobia is anxiety-based and paranoid thinking and interpersonal sensitivity driven.

Fear of missing out (FoMO) events was shown to be related to nomophobia by several studies (Gezgin et al., 2018; Ylldırım \& Correra, 2015). Defined as "pervasive apprehension that others might be having rewarding experiences from which one is absent, FoMO is characterized by the desire to stay continually connected with what others are doing" (Przybylski et al., 2013, p. 1841), nomophobia contains an emotional basis related with fear and anxiety. FoMO, in this current study was thought to show itself as interpersonal sensitivity; a kind of sensitivity that one has to be sensitive to others who might engage in rewarding activities.

This study is not without limitations. First, SCL-90 factors used in this study (anxiety, depression, obsessiveness, interpersonal sensitivity, paranoid ideation) were correlated with each other. In fact, although clinically important measurement, SCL-90 was reported to have highly correlated individual dimensions (Rief \& Fichter, 1992). Moreover, Strauman and Wetzler (1992) posited that SCL-90 scales were compiled on two large constructs, anxious-depression, and paranoid thinking. Given these findings, this study also confirmed the high correlations among 5 factors of SCL-90; however, its clinical significance is widespread in different cultures which 
make it superior than its statistical strength. Furthermore, these results were obtained from young adults who were university students and there were more females than males. These results could be generalized to similar groups. The study was a cross-sectional study. Further studies might explore the clinical representation of nomophobia in younger and older ages and might have longitudinal designs to track if there are time-dependent changes.

It has also been shown in this study that FoMO is also related to paranoid thinking, a feeling that fear of missing out encourages. In other words, the reason why people continue to touch their phones, check their phones and check their social media accounts might be paranoid thinking about what they might miss from other people's lives and the experiences they represent on their phones/social accounts. The fear of being excluded or deprived of the rewarding experiences of others may prompt a person to keep their phone close and to check it frequently, paranoid thinking that others might do something they do not know. This feeling might exacerbate people's sensitiveness to other people's lives and might further increase interpersonal sensitivity.

Authors' Contributions Statement The authors contributed all parts of the study.

Data Availability Statement The data that support the findings of this study are available from the corresponding author upon reasonable request.

\section{Declarations}

Conflict of Interest The authors declare no conflict of interest.

\section{References}

Adawi, M., Zerbetto, R., Re, T. S., Bisharat, B., Mahamid, M., Amital, H., del Puente, G., \& Bragazzi, N. L. (2019). Psychometric properties of the brief symptom inventory in nomophobic subjects: Insights from preliminary confirmatory factor, exploratory factor, and clustering analyses in a sample of healthy Italian volunteers. Psychology Research and Behavior Management, 12, 145-154. https://doi.org/10.2147/PRBM.S173282.

Adnan, M., \& Gezgin, D. M. (2016). A modern phobia: Prevalence of nomophobia among college students. Ankara University, Journal of Faculty of Educational Sciences, 49(1), 141-158.

Aljomaa, S. S., Qudah, M. F. A., Albursan, I. S., Bakhiet, S. F., \& Abduljabbar, A. S. (2016). Smartphone addiction among university students in the light of somevariables. Computers in Human Behavior, 61, 155-164. https://doi.org/10.1016/j.chb.2016.03.041.

American Psychiatric Association. (2013). Diagnostic and statistical manual of mental disorders (5th ed.). Washington, DC: American Psychiatric Association.

Apuke, O. D., \& Iyendo, T. O. (2018). University students' usage of the internet resources for research and learning: Forms of access and perceptions of utility. Heliyon, 4, e01052. https://doi.org/10.1016/j. heliyon.2018.e01052.

Arpaci, I. (2019). Relationships between early maladaptive schemas and smartphone addiction: The moderating role of mindfulness. International Journal of Mental Health and Addiction, 1-15. https://doi.org/10.1007/s11469-019-00186-y.

Babadi-Akashe, Z., Zamani, B. E., Abedini, Y., Akbari, H., \& Hedayati, N. (2014). The relationship between mental health and addiction to mobile phones among university students of Shahrekord, Iran. Addiction \& Health, 6(3-4), 93-99.

Bekaroğlu, E., \& Yılmaz, T. (2020). Nomophobia: Differential diagnosis and treatment. Current Approaches in Psychiatry, 12(1), 131-142. https://doi.org/10.18863/pgy.528897.

Bhattacharya, S., Bashar, M. A., Srivastava, A., \& Singh, A. (2019). Nomophobia: No mobile phone phobia. Journal of Family Medicine and Primary Care, 8(4), 1297-1300. https://doi.org/10. 4103/jfmpc.jfmpc_71_19.

Bian, M., \& Leung, L. (2014). Smartphone addiction: Linking loneliness, shyness, symptoms and patterns of use to social capital. Media Asia, 41(2), 159-176. https://doi.org/10.1080/01296612.2014.11690012.

Bianchi, A., \& Phillips, J. G. (2005). Psychological predictors of problem mobile phone use. Cyberpsychology \& Behavior, 8(1), 39-51.

Boonstra, T. W., Larsen, M. E., \& Christensen, H. (2015). Mapping dynamic social networks in real life using participants' own smartphones. Heliyon, 1(3), e00037. https://doi.org/10.1016/j. heliyon.2015.e00037.

Bragazzi, N. L., \& Del Puente, G. (2014). A proposal for including nomophobia in the new DSM-V. Psychology Research and Behavior Management, 7, 155-160. https://doi.org/10.2147/ PRBM.S41386.

Brysbaert, M. (2019). How many participants do we have to include in properly powered experiments? A tutorial of power analysis with reference tables. Journal of Cognition, 2(1), 16. https://doi.org/10. 5334/joc.72.

Dağ, I. (1991). Belirti Tarama Listesi (Scl-90-R)'nin Üniversite Öğrencileri için güvenirliği ve geçerliği [reliability and validity of the symptom check list (SCL-90-R) for university students]. Türk Psikiyatri Dergisi, 2(1), 5-12.

Derogatis, L. R. (1977). SCL-90: Administration, scoring and procedure manual-I for the revised version. Baltimore, MD: John Hopkins Univ., School of Medicine, Clinical Psychometrics Unit.

Derogatis, L. R. (1994). Symptom checklist-90-R: Administration, scoring, and procedures manual (3rd ed.). Minneapolis, MN: National Computer Systems.

Elhai, J. D., Levine, J. C., Dvorak, R. D., \& Hall, B. J. (2016). Fear of missing out, need for touch, anxiety and depression are related to problematic smartphone use. Computers in Human Behavior, 63, 509-516. https://doi.org/10.1016/j.chb.2016.05.079.

Elhai, J. D., Dvorak, R. D., Levine, J. C., \& Hall, B. J. (2017). Problematic smartphone use: A conceptual overview and systematic review of relations with anxiety and depression psychopathology. Journal of Affective Disorders, 207, 251-259. https://doi.org/10. 1016/j.jad.2016.08.030.

Elhai, J. D., Levine, J. C., O’Brien, K. D., \& Armour, C. (2018). Distress tolerance andmindfulness mediate relations between depression and anxiety sensitivity withproblematic smartphone use. Computers in Human Behavior, 84, 477-484. https://doi.org/10.1016/j.chb.2018. 03.026 .

George, D., \& Mallery, M. (2010). SPSS for windows step by step: A simple guide and reference, 17.0 update (10a ed.). Boston: Pearson.

Gezgin, D. M., Hamutoglu, N. B., Sezen-Gultekin, G., \& Gemikonakli, O. (2018). Relationship between nomophobia and fear of missing out among Turkish university students. Cypriot Journal of Educational Sciences, 13(4), 549-561.

Han, S., Kim, K. J., \& Kim, J. H. (2017). Understanding nomophobia: Structural equation modeling and semantic network analysis of 
smartphone separation anxiety. Cyberpsychology, Behavior and Social Networking, 20(7), 419-427. https://doi.org/10.1089/cyber. 2017.0113.

Harwood, J., Dooley, J. J., Scott, A. J., \& Joiner, R. (2014). Constantly connected-the effects of smart-devices on mental health. Computers in Human Behavior, 34, 267-272. https://doi.org/10.1016/j.chb. 2014.02.006.

Head, M., \& Ziolkowski, N. (2012). Understanding student attitudes of mobile phone features: Rethinking adoption through conjoint, cluster and SEM analyses. Computers in Human Behavior, 28(6), 23312339. https://doi.org/10.1016/j.chb.2012.07.003.

International Telecommunication Union. (2017). Measuring the information society report. Geneve, Switzerland: International Telecommunication Union.

Jilisha, G., Venkatachalam, J., Menon, V., \& Olickal, J. J. (2019). Nomophobia: A mixed-methods study on prevalence, associated factors, and perception among college students in Puducherry, India. Indian Journal of Psychological Medicine, 41(6), 541-548. https://doi.org/10.4103/IJPSYM.IJPSYM_130_19.

King, A. L. S., Valença, A. M., \& Nardi, A. E. (2010). Nomophobia: The mobile phone in panic disorder with agoraphobia: Reducing phobias or worsening of dependence? Cognitive Behavioral Neurology, 23, 52-54. https://doi.org/10.2174/1745017901410010028.

King, D. L., Delfabbro, P. H., Griffiths, M. D., \& Gradisar, M. (2012). Cognitive-behavioral approaches to outpatient treatment of internet addiction in children and adolescents. Journal of Clinical Psychology, 68, 1185-1195. https://doi.org/10.1002/jclp.21918.

King, A. L. S., Valença, A. M., Silva, A. C., Sancassiani, F., Machado, S., \& Nardi, A. E. (2014). Nomophobia: Impact of cell phone use interfering with symptoms and emotions of individuals with panic disorder compared with a control group. Clinical Practice Epidemiology in Mental Health, 10, 28-35. https://doi.org/10. 2174/1745017901410010028.

Kuscu, T. D., Gumustas, F., Rodopman Arman, A., \& Goksu, M. (2020). The relationship between nomophobia and psychiatric symptoms in adolescents. International Journal of Psychiatry in Clinical Practice, 1-6. https://doi.org/10.1080/13651501.2020.1819334.

Lemola, S., Perkinson-Gloor, N., Brand, S., Dewald-Kaufmann, J. F., \& Grob, A. (2015). Adolescents' electronic media use at night, sleep disturbance, and depressive symptoms in the smartphone age. Journal of Youth and Adolescence, 44(2), 405-418. https://doi.org/ 10.1007/s10964-014-0176-x.

Leonardi, P., Leonardi, M. E., \& Hudson, E. (2006). Culture, organization, and contradiction in the social construction of technology: Adoption and use of the cell phone across three cultures. In A. Kavoori \& N. Arceneaux (Eds.), The cell phone reader: Essays in social transformation (pp. 205-225). New York: Peter Lang.

Lopez-Fernandez, O., Kuss, D. J., Romo, L., Morvan, Y., Kern, L., Graziani, P., Rousseau, A., Rumpf, H. J., Bischof, A., Gässler, A. K., Schimmenti, A., Passanisi, A., Männikkö, N., Kääriänen, M., Demetrovics, Z., Király, O., Chóliz, M., Zacarés, J. J., Serra, E., Griffiths, M. D., Pontes, H. M., Lelonek-Kuleta, B., Chwaszcz, J., Zullino, D., Rochat, L., Achab, S., \& Billieux, J. (2017). Self-reported dependence on mobile phones in young adults: A European crosscultural empirical survey. Journal of Behavioral Addictions, 6(2), 168-177. https://doi.org/10.1556/2006.6.2017.020.

Packham, A. (2015). Nomophobia: The four stages of smartphone separation anxiety. Retrieved from https://bit.ly/37B6j66 on 4 February 2021.

Przybylski, A. K., Murayama, K., DeHaan, C. R., \& Gladwell, V. (2013). Motivational, emotional, and behavioral correlates of fear of missing out. Computers in Human Behavior, 29(4), 1841-1848. https://doi. org/10.1016/j.chb.2013.02.014.

Rief, W., \& Fichter, M. (1992). The symptom check list SCL-90-R and its ability to discriminate between dysthymia, anxiety disorders, and anorexia nervosa. Psychopathology, 25(3), 128-138. https://doi. org/10.1159/000284763.

Rodríguez-García, A. M., Moreno-Guerrero, A. J., \& López Belmonte, J. (2020). Nomophobia: An individual's growing fear of being without a smartphone - a systematic literature review. International Journal of Environmental Research and Public Health, 17(2), 580. https:// doi.org/10.3390/ijerph17020580.

Sales, H. F. S., Silva, F. M. D. S. M., \& Lima, B. D. J. L. (2018). Adaptação da escala de uso compulsivo de Internet para avaliar dependência de smartphone. Avances en psicología latinoamericana, 36(1), 155-166. https://doi.org/10.12804/ revistas.urosario.edu.co/apl/a.4649.

Șar, A. H., \& Iș1klar, A. (2012). Problemli mobil telefon kullanım ölçeğinin Türkçeye uyarlaması. International Journal of Human Sciences, 9(2), 264-275.

Siddiqui, M., \& Ali, A. Z. (2015). Addictive cell phone usage: The relationship between impulsiviness and behavioral addiction. Pakistan Journal of Psychology, 46(2), 53-67.

Strauman, T. J., \& Wetzler, S. (1992). The factor structure of SCL-90 and MCMI scale scores: Within-measure and interbattery analyses. Multivariate Behavioral Research, 27(1), 1-20. https://doi.org/10. 1207/s15327906mbr2701_1.

Thomée, S., Härenstam, A., \& Hagberg, M. (2011). Mobile phone use and stress, sleep disturbances, and symptoms of depression among young adults-a prospective cohort study. BMC Public Health, 11(66), 1-11.

Wolniewicz, C. A., Tiamiyu, M. F., Weeks, J. W., \& Elhai, J. D. (2018). Problematic smartphone use and relations with negative affect, fear of missing out, and fear of negative and positive evaluation. Psychiatry Research, 262, 618-623. https://doi.org/10.1016/j. psychres.2017.09.058.

Yen, C. F., Tang, T. C., Yen, J. Y., Lin, H. C., Huang, C. F., Liu, S. C., \& Ko, C. H. (2009). Symptoms of problematic cellular phone use, functional impairment and its association with depression among adolescents in Southern Taiwan. Journal of Adolescence, 32(4), 863-873. https://doi.org/10.1016/j.adolescence.2008.10.006.

Yildirim, C., \& Correia, A. P. (2015). Exploring the dimensions of nomophobia: Development and validation of a self reported questionnaire. Computers in HumanBehavior, 49, 130-137. https://doi. org/10.1016/j.chb.2015.02.059.

Yildirim, C., Sumuer, E., Adnan, M., \& Yildirim, S. (2016). A growing fear: Prevalence of nomophobia among Turkish college students. Information Development, 32(5), 1322-1331. https://doi.org/10. 1016/j.chb.2015.02.059.

Yildiz Durak, H. (2019). Investigation of nomophobia and smartphone addiction predictors among adolescents in Turkey: Demographic variables and academic performance. The Social Science Journal, 56(4), 492-517. https://doi.org/10.1016/j.soscij.2018.09.003.

Yogesh, S., Abha, S., \& Priyanka, S. (2014). Short communication mobile usage and sleep patterns among medical students. Indian Journal of Physiological Pharmacology, 58(1), 100-103.

Publisher's note Springer Nature remains neutral with regard to jurisdictional claims in published maps and institutional affiliations. 